\title{
Numerical Modal Analysis of the Turbo-jet Engine Rotor Blades
}

Ján Vavro, Ján Vavro jr., Marta Kianicová, Alena Vavrová, Beáta Pecušová

Faculty of Industrial Technologies in Púchov, Alexander Dubček University of Trenčín. I. Krásku 491/30, 02001 Púchov. Slovac Republic.E-mail: jan.vavro@fpt.tnuni.sk, jan.vavro.jr@fpt.tnuni.sk, marta.kianicova@tnuni.sk, alena.vavrova@azet.sk, beata.pecusova@fpt.tnuni.sk

The given paper is closely connected with the numerical modal analysis of eigenfrequencies and eigenshapes for turbine blades of the turbojet engine with the help of the mathematic modelling. The mathematic model was created in Pro-Engineer program and it was subsequently created to the ANSYS program in order to apply finite element method. Distribution of the stress in the turbine blades is presented in [Pa]. The presented results of the eigenshapes and distribution of the stress are obtained in the graphic form.

Keywords: modal analysis, eigenfrequencies, eigenshapes, stress, finite element method

\section{Introduction}

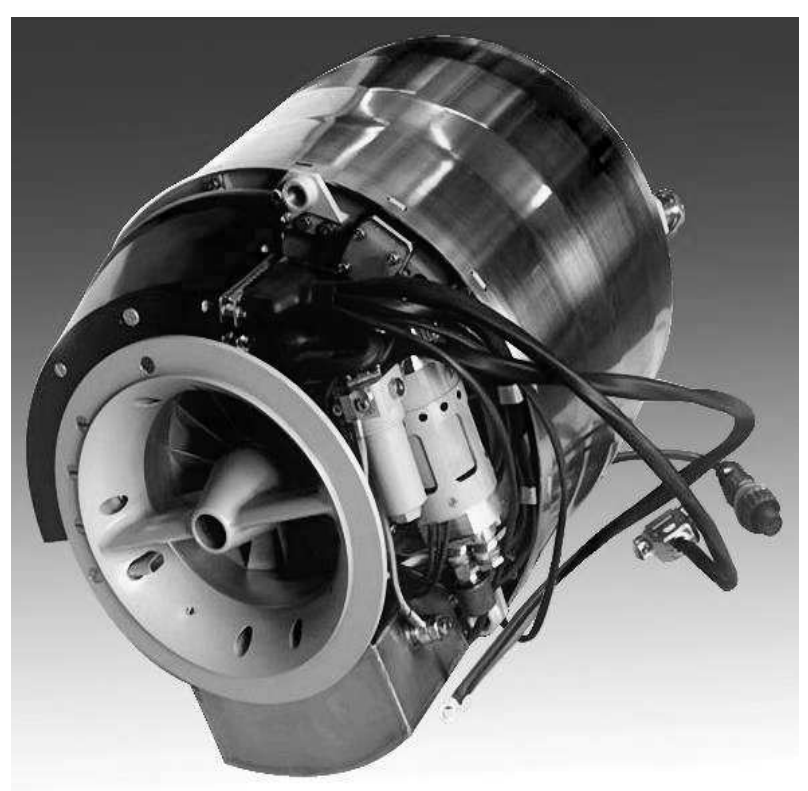

Fig. 1 Image of turbojet engine TJ 100

The turbo-jet engine TJ 100 is normally used as a small power driving unit which can be installed as auxiliary engine into light and ultralight planes, sailplanes as well as gliders. The design of this small auxiliary turbine engine TJ 100 can be seen hereinafter (Fig. 1). TJ 100 is single-shaft engine with single-stage radial compressor, annular combustion chamber and single-stage axial turbine which consists of rotating integral guide (distribution) and turbine blade wheel (it is starter-generator) together with output nozzle.

The intake air is compressed in the radial compressor wheel and then it pass through the radial and axial diffuser into the annular combustion chamber where it is mixed together with the fuel. The mentioned fuel is sprayed by the fuel nozzles. The residue gases of combustion which occurs during the burning process of fuel in the combustion chamber expand through the single-stage axial turbine and they get out through the output nozzle at the high speed into the atmosphere and this is the way for creation of motor thrust. The compressor running is provided by axial turbine. Rotor is placed on ball bearings which must be lubricated with pressure oil.

The basic operating parameters for turbojet engine TJ 100:

- Operating engine speed (revolutions per minute):

- idle engine speed - $30000 \mathrm{rpm}$

- maximum output engine speed (100\%) - 60000 rpm

- Maximum fuel consumption is 60 litres per hour

- Temperature of gas in front of turbine is about $890{ }^{\circ} \mathrm{C}$

Stator as well as rotor turbine blades are made of nickel superalloy Inocel 713 LC. The chemical composition of this nickel superalloy is shown in table 1 .

\section{The computational model}

The computational model of rotating turbine blade wheel is shown in fig. 2.

\section{Tab. 1 The chemical composition of nickel superalloy}

\begin{tabular}{|l|l|l|l|l|l|l|l|l|l|}
\hline Chemical element & $\mathrm{C}$ & $\mathrm{Cr}$ & $\mathrm{Ti}$ & $\mathrm{Al}$ & $\mathrm{B}$ & $\mathrm{Zr}$ & $\mathrm{Nb}$ & $\mathrm{Mo}$ & $\mathrm{Ni}$ \\
\hline wt.\% & 0.05 & 12.08 & 0.75 & 5.91 & 0.01 & 0.10 & 2.02 & 4.58 & bal. \\
\hline
\end{tabular}




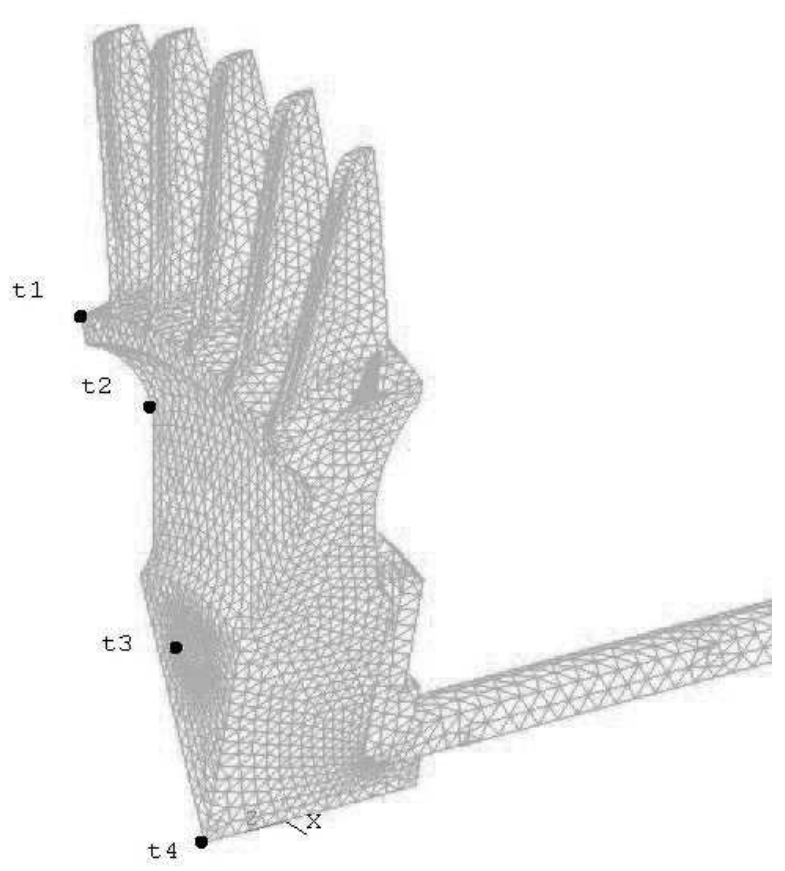

Fig. 2 Model of rotating blade wheel

\section{The calculation of the blade construction lo- aded by the dynamic loading}

The mathematical model for turbine blades was created with eight nodal volume elements. Stability equations $[1,2,3,9]$ were solved using (1):

$$
[\mathbf{M}]\{\ddot{\mathbf{u}}\}+[\mathbf{C}]\{\dot{\mathbf{u}}\}+[\mathbf{K}]\{\mathbf{u}\}=\{\mathbf{f}(\mathrm{t})\} .
$$

where $\mathbf{M}$ is the mass matrix, $\mathbf{C}$ is the damping matrix, $\mathbf{K}$ is the stiffness matrix, $\{\mathbf{f}(\mathrm{t})\}$ is the time varying load vector and $\{\mathbf{u}\},\{\dot{\mathbf{u}}\},\{\ddot{\mathbf{u}}\}$ are the displacement, velocity and acceleration vectors, respectively.

Dynamic analysis of the blade construction includes solution of the stability equations (1). Stress distribution $[4,7,8]$ is presented in $[\mathrm{Pa}]$ and it can be seen in the Fig. 3 and Fig.4. On the Fig. 5 is total displacement.

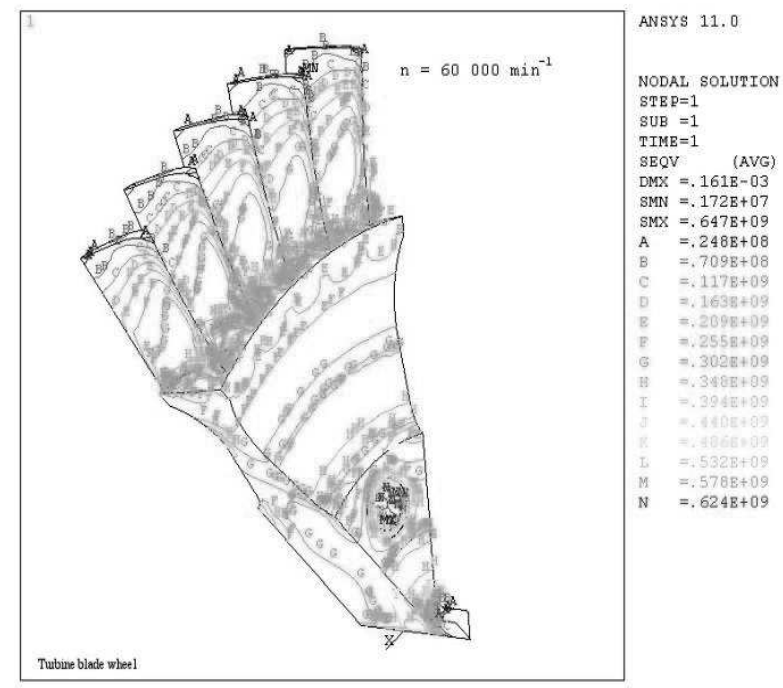

Fig. 3 Stress distribution [Pa]

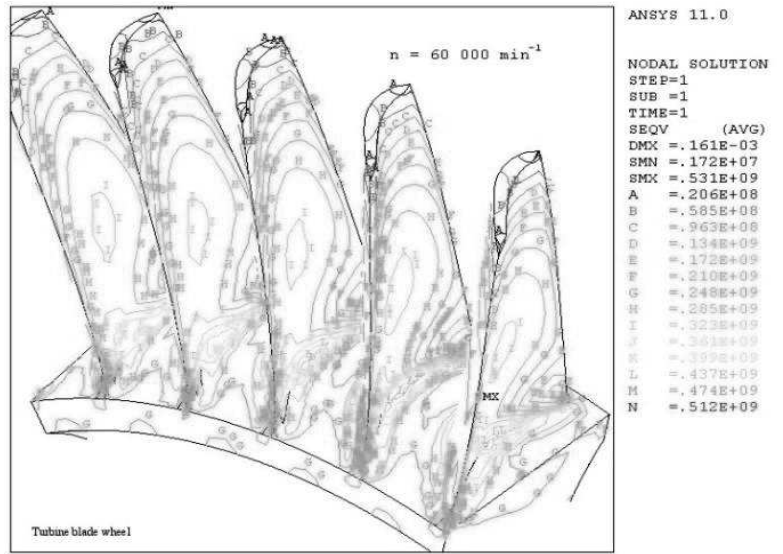

Fig. 4 Stress distribution [Pa ]

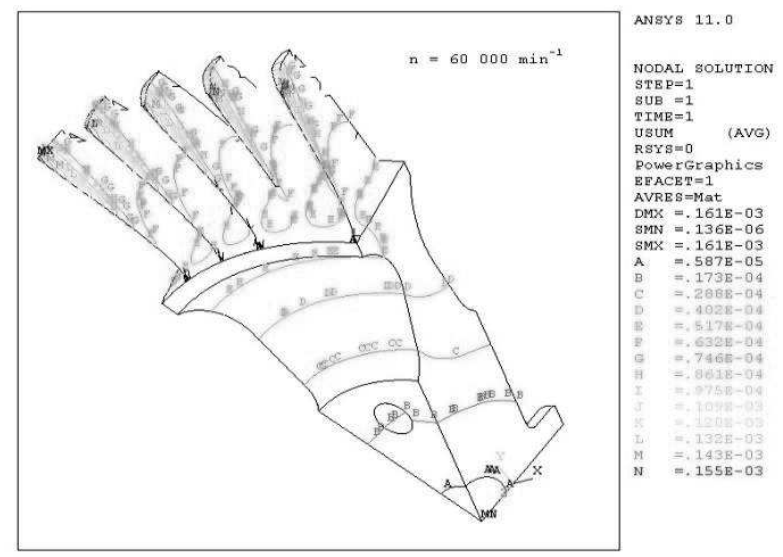

Fig. 5 Total displacement $[\mathrm{m}]$

The figure 6 shows the course of given temperatures for individual points of rotating blade wheel according to the figure 2 .

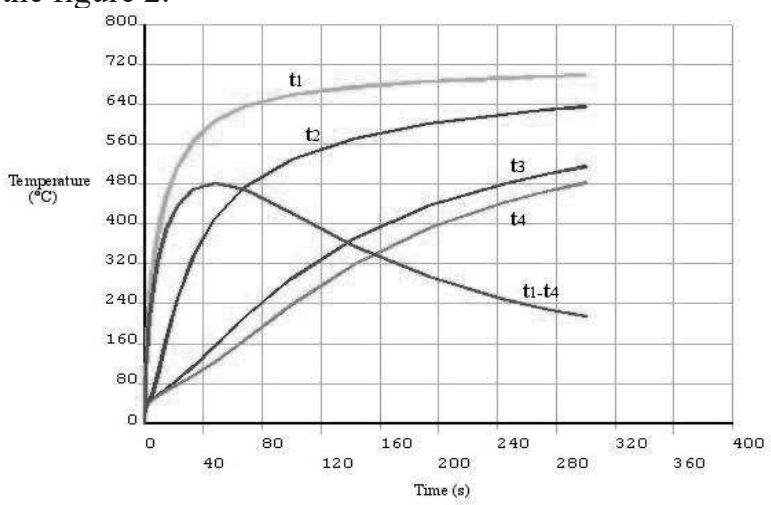

Fig. 5 The course of temperatures for individual points of rotating blade wheel

\section{The calculation of the eigenfrequencies and eigenshapes for turbine blades}

Mathematical model can be expressed in form (1). Modal and frequency analysis $[5,6,10]$ were done according to known equation in the form

$$
\left(-\omega_{i}^{2}[\mathbf{M}]+[\mathbf{K}]\right) \cdot\left\{\Phi_{i}\right\}=\{0\} .
$$

where $\omega_{i}$ is i-th eigenfrequency, $\left\{\Phi_{i}\right\}$ is the eigenvector representing the nodal shape of $\mathrm{i}$-th eigenfreque- 
ncy. We calculated eigenfrequences and from the eigenfrequences, there were calculated frequency characteristics with the modal damping $\xi=0.001$. The motion equation for i-th eigenshape is in accordance with:

$$
\ddot{x}_{i}+2 \xi_{i} \omega_{i} \dot{x}_{i}+\omega_{i}^{2} x_{i}=\{\Phi\}_{i}^{T}\{f\} \text {. }
$$

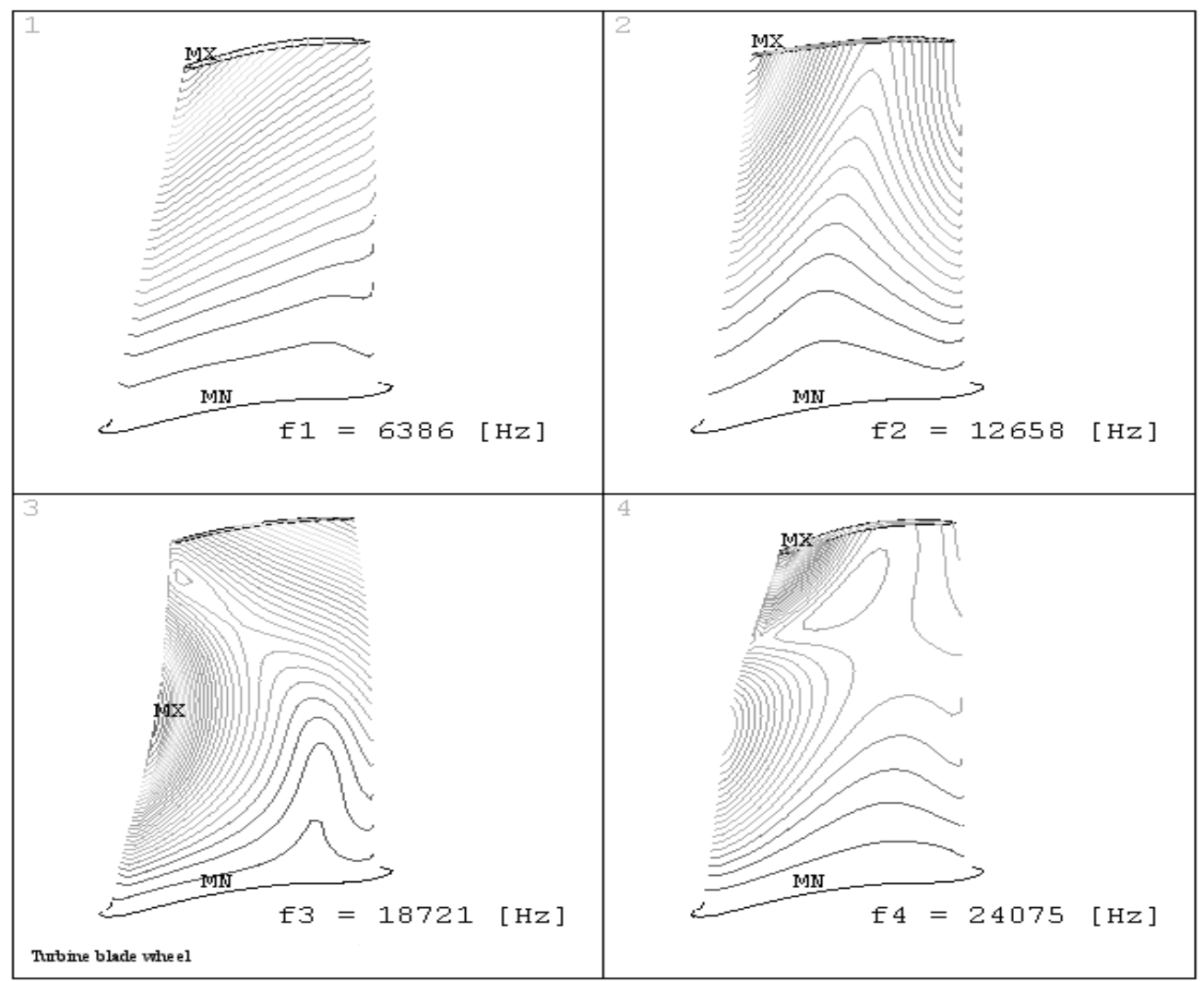

ANSYS 11.0

NODAL SOLUTION

$\mathrm{STEP}=1$

SUB $=1$

$\mathrm{FREQ}=6386$

US UM

(AVG)

RSY S $=0$

PowerGraphics

$\mathrm{EFACE} T=1$

AVRE S=Mat

$\mathrm{DMX}=63.937$

SMX $=63.937$

1. 066

3. 197

7.459

9. 591

13.853

18.116

20.247

24.509

26.641

30.903

35.165

37.297

41.559

43.69

52.215

54.347

58.609

62.872

Fig. 6 The first four eigenshapes of vibrations

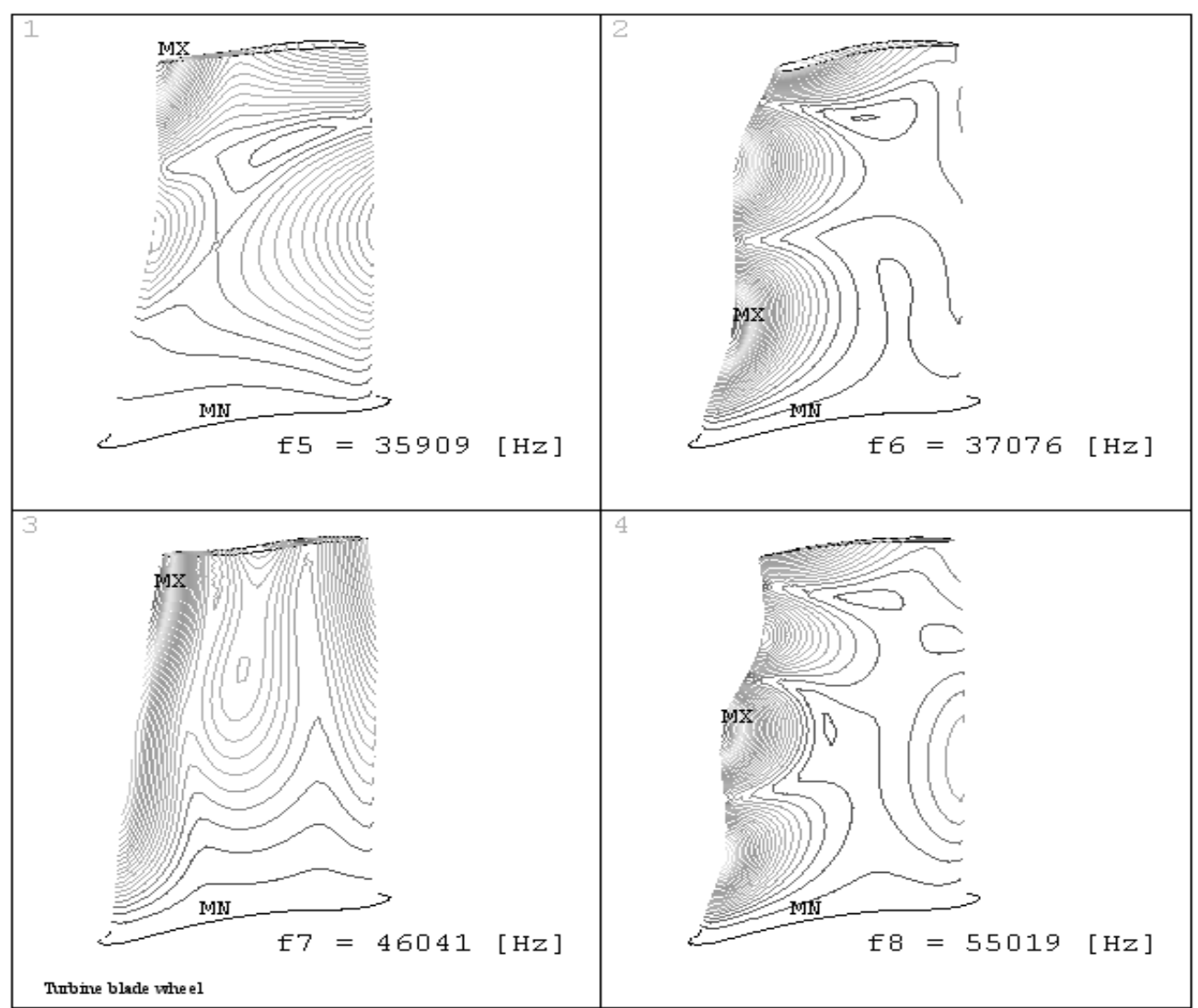

ANSYS 11.0

NODAL SOLUTION

ST E $P=1$

SUB $=5$

$F R E Q=35909$

US UM

(AVG)

RSYS $=0$

PowerGraphics

E F ACE T $=1$

AVRE $\mathrm{S}=$ Mat

$\mathrm{DMX}=95.086$

SMX $=95.086$

1. 585

4. 754

11.093

14.263

20.602

26.941

30.11

36.45

39. 619

45.958

52.297

55.467

61.806

64.975

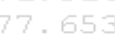

80.823

87.162

93.501

Fig. 7 Further four eigenshapes of vibrations 
This relationship is generalized problem of the eigenvalues where solution is made by the semi-automaticspace iterative method. This method is based on the idea of the inverse iteration conversion with several vectors at the same time. In Fig. 6 and Fig. 7 we can see first eight eigenfrequencies of vibrations calculated by the help of the underspace method.

\section{Summary}

The results obtained on the base of frequency analysis, thermal loading of turbine blades as well as distribution of main stresses pointed out the areas for which the loading of turbine wheel and blades is the highest. The given results can help us to specify the areas representing the possible initiation and distribution of crack relating to turbine blades. Figure 7 represents such crack of turbine wheel and figure 8 represents fracture surface of the blade.

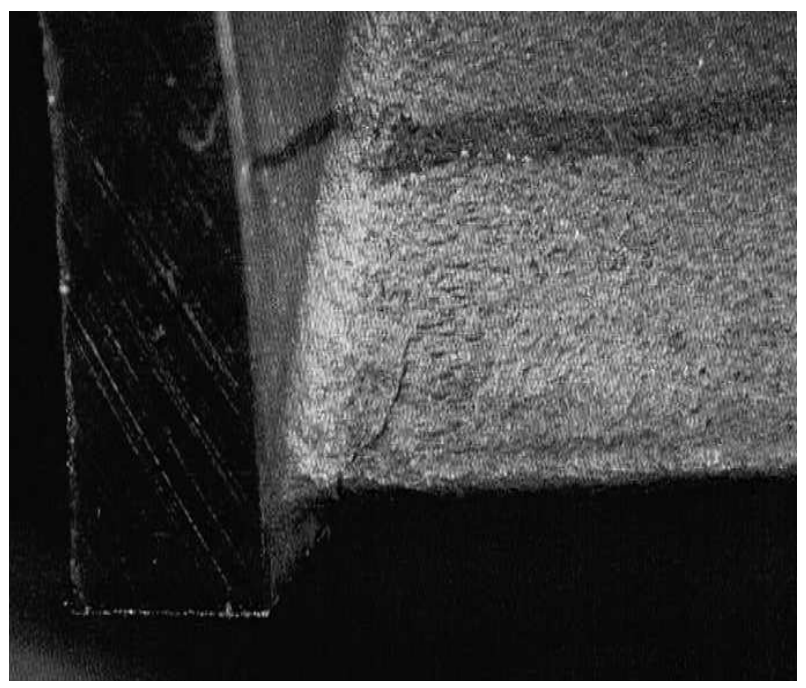

Fig. 6 The turbine wheel with the crack of blade

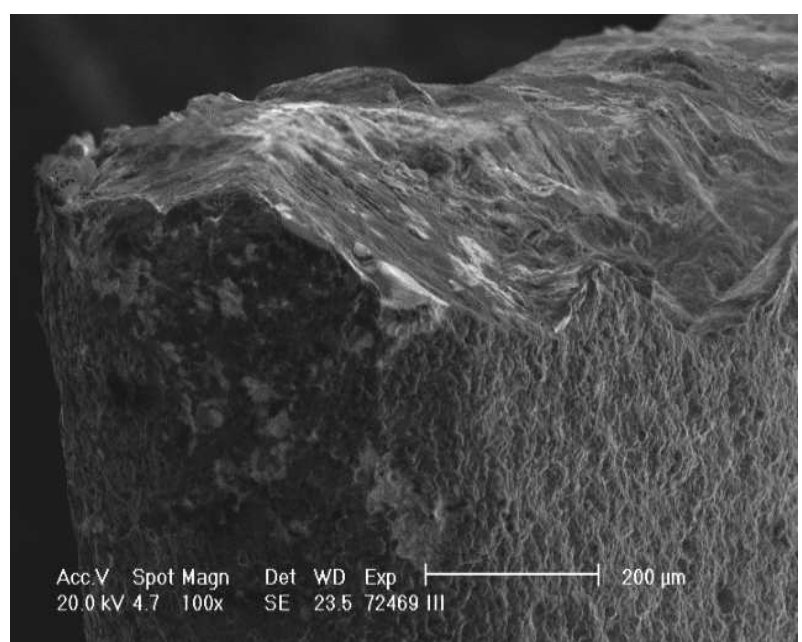

Fig. 7 Fracture surface of the blade

\section{Acknowledgement}

This work was supported by the Slovak Grant Agency VEGA 1/0649/17, KEGA 007TnUAD-4/2017, and resulted from the project "Center for quality testing and diagnostics of materials", ITMS code 26210120046 relating to the Operational Program Research and Development funded from European Fund of Regional Development.

\section{References}

[1] AZAR, J.,J. (1972). Matrix Structural Analysis, Pergamon Press, New York.

[2] BATHE, K., J. (1982). Finite element procedures in engineering analysis. Englewod Cliffs.

[3] BATHE, K., J., WILSON, E., L., PETERSON, F., E. (1973). SAP-IV, A Structural Analysis Program for Static and Dynamic Response of Linear Systems, Berkeley.

[4] MÁRIA BLATNICKÁ, MIROSLAV BLATNICKÝ, JÁN DIŽO, MILAN SÁGA, (2018). Comparison of Analytical Stress Analysis and Numerical Calculation of Mobile Work Machine Part, Manufacturing Technology, Volume 18, ISSN 1213-2489, pp.190-193.

[5] JÁN DIŽO, JOZEF HRUŠINEC, MIROSLAV BLATNICKÝ, (2018). Computational of Modal Properties of Two Types of Freight Wagon Bogie Frames Using the Finite Element Method, Manufacturing Technology, Volume 18, ISSN 12132489, pp. 208-214.

[6] JAN DIZO, MIROSLAV BLATNICKÝ, (2019). Evaluation of Vibrotional Properties of a Threewheeled Vehicle in Terms of Comfort, Manufacturing Technology, Volume 19, ISSN 12132489, pp. 197-203.

[7] FRANTISEK KLIMENDA, JOSEF SOUKUP, MILAN ZMINDAK, (2016). Deformation of Aluminium Thin Plate, Manufac- turing Technology, Volume 16, , ISSN 1213-2489, pp. 124-129.

[8] ZUZANA STANKOVIČOVÁ, VLADIMÍR DEKÝŠ, PAVOL NOVÁK, MILAN SAPIETA, (2015). Numerical Simulation of Ther-moelastic Stress Analysis, Manufacturing Technology, Volume 15, , ISSN 1213-2489, pp. 925-930.

[9] TEPLÝ, B. (1990). Metóda konečných prvkov. VUT Brno.

[10] YONGYI LIAO, BAIYU LIAO, (2019). Dynamics Modeling and Modal Analysis of Machine ool Considering Joints Parameters, Manufacturing Technology, Volume 19, ISSN 1213-2489, pp. 267-272. 